\title{
SOME PHARMACOLOGIC TREATMENT OPTIONS IN LATER- LIFE ANXIETY DISORDERS
}

\author{
Mariana Arnaudova. \\ Third Psychiatric Clinic, UMHAT "St. Marina", Department of Psychiatry, \\ Medical University - Varna, Bulgaria
}

\section{SUMMARY}

Most recommendations for treatment of anxiety in later life are based on evidence, derived from studies of younger populations. An important challenge is the high psychic and physical comorbidity of primary anxiety disorders.

The aim of our study was to examine the pharmacological treatment of elderly patients in acute psychiatry setting, presenting with anxiety disorder.

All subjects underwent clinical psychiatric examination and evaluation according to ICD-10 and DSMIV criteria for an anxiety disorder and depression. The patients were examined also for a physical comorbidity.

Depressive-anxious or comorbid with depression anxious patients prevailed. Primary solitary anxiety disorders were less seen. High physical comorbidity was registerd.

Pharmacologic treatment consisted mostly of benzodiazepines and antidepressants. A considerable number of patients received Quetiapine in their therapeutic plans.

Pharmacologic treatment in elderly patients with anxiety disorders should be precisely administered. Standard pharmacotherapy of anxiety disorders for a number of elderly patients needs to be modified. Further research is needed to determine the most appropriate safe and effective treatment model.

Key words: anxiety, later life, elderly, therapy

\section{INTRODUCTION:}

Anxiety symptoms and disorders are common in later life. Subthreshold anxiety symptomology is even higher. The treatment of anxiety disorders is in the focus of discussion from different points of view. The rational use of pharmacological treatment in generalized anxiety disorders is still a matter of debate due to the uncertainties concerning the nature, diagnostic criteria and target-symptoms of this frequent and potentially invalidating disorder (1). An important challenge is the high comorbidity of primary anxiety disorders with depression (nearly $50 \%)(2,3)$. Elderly anxious patients, especially comorbid with depression or physical illness have worser recovery rates and higher relapse than younger adults. Treatment should have several basic targets adequate to these for younger patients: acute control of symptoms, remission of core symptoms, alleviation of comorbid conditions, relapse prevention.

Approved medications for the treatment of generalized anxiety disorder include benzodiazepines such as alprazolam and clonazepam, the 5-HT1A receptor agonist buspirone, the selective serotonin reuptake inhibitors (SSRIs) paroxetine and escitalopram, and the selective serotonin-norepinephrine inhibitor venlafaxine. Baldwin (2010) notifies that recent evidence-based guidelines for the pharmacological management of patients with GAD have recommended initial treatment with either a selective serotonin reuptake inhibitor (SSRI) or a serotonin-norepinephrine reuptake inhibitor (SNRI). However, there is much room for improvement in both the efficacy and the tolerability of treatment. Future research is needed about the optimal duration of treatment after a satisfactory initial response and identification of certain patient subgroups (4).

Most recommendations for treatment of anxiety disorders in elderly patients are based on data, derived from studies of younger populations, due to lack of age-specific or long-term data in elderly population (5). Benzodiazepines are the most common medication treatment for late life anxiety; SSRIs are safely used but have not completely replaced benzodiazepines as a treatment for anxiety in older people (6). There is a need for more effective research on evidence-based treatments for late life anxiety (7). Lenze (2005) points out that late-life GAD is poorly recognized and undertreated, and that the treatment of this disorder needs further study (8). Sramek (2002) notifies that a number of potentially new pharmacotherapies, including newer serotonin 5-HT1A receptor agonists, cholecystokinin receptor antagonists, neurokinin receptor antagonists, gabapentin and its analogues, and gamma-aminobutyric acid (GABA) A receptor modulators are still in the process of investigation and recognition (9).

The aim of our study was to examine the pharmacological treatment of elderly patients in acute psychiatry setting, presenting with anxiety disorder.

\section{METHOD:}

Eighty patients, aged 60 and above, entered the study. All subjects underwent clinical psychiatric examination and evaluation according to ICD-10 and DSM-IV criteria for an 
anxiety disorder and depression. The patients were examined also for a physical comorbidity.

\section{RESULTS AND DISCUSSION:}

Out of all patients with anxiety symptoms, depressive-anxious (53.75\%) and comorbid with depression anxious states $(36.25 \%)$ prevailed. Next were solitary GAD $(6.25 \%)$ and patients with panic disorder (3.75\%) (Fig.1). We found out high physical comorbidity in terms of cardiovascular, endocrine, gastrointestinal and neurological issues (Tabl. 1).

Table 1. Physical comorbiduty
Fig.1. Anxiety pattern prevalence

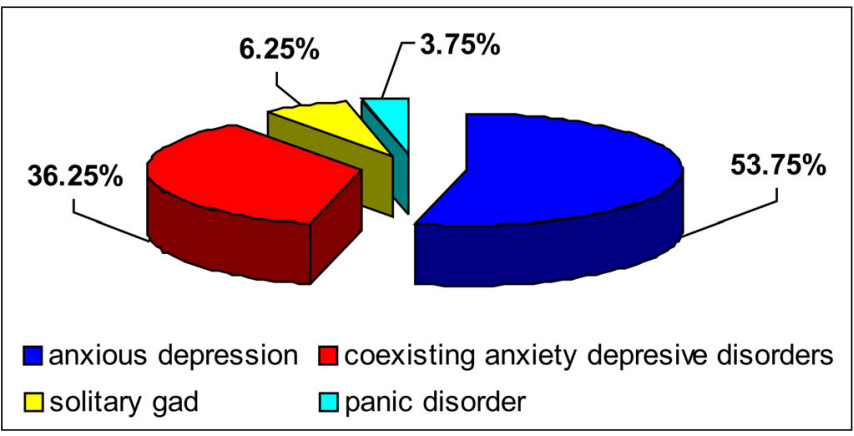

\begin{tabular}{|l|c|c|}
\hline SYSTEM & MEDICAL CONDITION & NUMBER OF PATIENTS \\
\hline CARDIOVASCULAR & $\begin{array}{r}\text { ARTERIALHYPERTENSION, } \\
\text { ISCHAEMIC HEART DISEASE, } \\
\text { MYOCARDIAL INFARCTION }\end{array}$ & 46 patients $(57,5 \%)$ \\
\hline ENDOCRINE & $\begin{array}{r}\text { DIABETES MELLITUS, } \\
\text { HYPER/ HYPOTHYROIDISM }\end{array}$ & 11 patients $(13,75 \%)$ \\
\hline NEUROLOGICAL & $\begin{array}{r}\text { STRATEGIC STROKES, } \\
\text { PARKINSON'S DISEASE, DEMENTIA }\end{array}$ & 9 patients $(11,25 \%)$ \\
\hline GASTROINTESTINAL & GER & 7 patients $(8,75 \%)$ \\
\hline PULMONARY & $\begin{array}{r}\text { CHRONIC OBSTRUCTIVE } \\
\text { PULMONARY DISEASE, PNEUMONIA }\end{array}$ & 6 patients $(7,5 \%)$ \\
\hline
\end{tabular}

Pharmacologic treatment consisted mostly of benzodiazepines (85.29\%) and SSRI's (64.70\%). A considerable number of patients $(41.17 \%)$ received Quetiapine in their therapeutic plans (Fig. 2).

Fig.2. Summarized pharmacologic treatment options

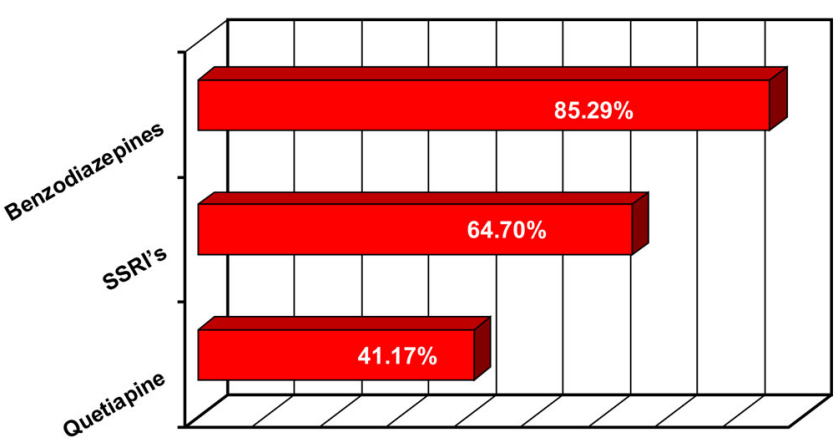

As it is well known, benzodiazepines have a more rapid onset and exhibit benefits on short-term relief of anxiety. In our patients they were administered since the beginning of the therapy at bed time with caution for possible unfavorable side-effects, such as sedation, confusion and increased risk of falls. Benzodiazepines cover the period of time while antidepressants show their benefit, which comes later. We support the opinion that, their sole administration should be precised to a primary anxiety disorder, while in depressiveanxious patients an antidepressant should be included.

In our practice Selective serotonin reuptake inhibitors (SSRI's)- paroxetine, escitalopram, sertraline proved to be efficacious in reaching a good therapeutic response in depression and most anxiety disorders. An advantage of these drugs is that they are administered in once-daily doses and are generally well tolerated. The doses basically are up to T! from these for younger patients but we usually apply an individual approach, as we closely monitor the patients. Lately we gather much experience with agomelatine (up to $50 \mathrm{mg}$ ) in depressive anxious states.

A considerable number of patients received Quetiapine in their therapeutic plans. We registered significant symptom relief in elderly patients with anxious depression and with generalised anxiety disorder (GAD). Safety and tolerability findings were consistent with the known safety profile of quetiapine. The common side effects of SSRI's (sexual dysfunction, nausea, sleep problems, fatigue, diarrhea, and nervousness) usually were short-lived. Our results are consistent with the positive results previously reported from other studies conducted with quetiapine XR in GAD in younger (10) and in MDD and GAD in elderly adults $(11,12)$. However, the long-term risk and benefit of atypical antipsychotics in the treatment of GAD is yet to be determined (13). 
Anxiety disorders are often associated with common age-related medical and chronic conditions such as asthma, thyroid disease, coronary artery disease, dementia, and sensory loss (14). As we mentioned, a high physical comorbidity was registered among our patients. We share the opinion of some authors that common physical illnesses, drugs and substances can manifest themselves as symptoms of anxiety. For that reason, pharmacologic treatment in elderly patients with anxiety disorders should be based on accurate diagnosis, age, history of prior drug treatment response, physical and psychiatric comorbidity, especially with depression (15). A drug that we prefer in physically comorbid patients, with the least effect on the cytochrome P-450 system, an important source of drug-drug intereactions, is escitalopram

The rule we follow when dealing with elderly patients is that drug dose ranges, side effect profiles and comorbidity should be considered.

\section{CONCLUSIONS:}

Anxiety is a common problem in late life. Disentangling anxiety from depression is difficult during assessment. Comorbidity with medical illnesses is high. Anxiety symptoms and disorders are generally associated with decreased physical activity, poorer self-perception of health and decreased life satisfaction. Further research is needed to determine the most appropriate safe and effective treatment model.

\section{REFERENCES:}

1. Boulenger J, Capdevielle D. Pharmacological treatment of generalized anxiety disorders: rationale and limitations. [in French] Encephale. 2007 Jan-Feb; 33(1):84-94. [PubMed]

2. Schoevers RA, Beekman AT, Deeg DJ, Jonker C, van Tilburg W. Comorbidity and risk-patterns of depression, generalised anxiety disorder and mixed anxiety-depression in later life: results from the AMSTEL study. Int $J$ Geriatr Psychiatry. 2003 Nov;18(11): 994-1001 [PubMed] [CrossRef]

3. Byers AL, Yaffe K, Covinsky KE, Friedman MB, Bruce ML. High Occurence of Mood and Anxiety Dsorders Among Older Adults. Arch Gen Psychiatry. 2010 May;67(5):489496. [PubMed] [CrossRef]

4. Baldwin DS, Ajel KI, Garner M. Pharmacological treatment of generalized anxiety disorder. Curr Top Behav Neurosci. 2010; 2:453-67. [PubMed]

5. Diefenbach GJ, Goethe J. Clinical Interventions for Late-Life Anxious Depression. Clin Interv Aging. 2006 Mar; 1(1):41-50. [PubMed]

6. Keene MS, Eaddy MT, Nelson WW, Sarnes MW. Adherence to Paroxetine CR compared with Paroxetine IR in a Medicare-eligible population with anxiety disorders. Am J Manag Care. 2005 Oct;11(12 Suppl):S362-369.
[PubMed]

7. Mitte K. Meta-analysis of cognitive-behavioral treatments for Generalized Anxiety Disorder: A comparison with pharmacotherapy. Psychol Bull. 2005 Sep;131(5):785-795. [PubMed] [CrossRef]

8. Lenze EJ, Mulsant BH, Mohiman J, Shear MK, Dew MA, Schulz R, et al. Generalized anxiety disorder in late life: lifetime course and comorbidity with major depressive disorder. Am J Geriatr Psychiatry. 2005 Jan; 13(1):77-80. [PubMed]

9. Sramek JJ, Zarotsky V, Cutler NR. Generalized anxiety disorder: treatment options. Drugs. 2002; 62(11):1635-48. [PubMed]

10. Bandelow B, Chouinard G, Bobes J, Ahokas A, Eggens I, Liu S, et al. Extended-release quetiapine fumarate (quetiapine XR): a once-daily monotherapy effective in generalized anxiety disorder. Data from a randomized, double-blind, placebo-and active-controlled study. Int $J$ Neuropsychopharmacol. 2010 Apr;13(3):30520. [PubMed] [CrossRef]

11. Katila H, Mezhebovsky I, Mulroy A, Berggren L, Eriksson H, Earley W, et al. Randomized, Double-Blind Study of the Efficacy and Tolerability of
Extended Release Quetiapine Fumarate (Quetiapine XR) Monotherapy in Elderly Patients With Major Depressive Disorder. Am J Geriatr Psychiatry. 2012 Jun 7. [Epub ahead of print] [PubMed]

12. Mezhebovsky I, Mдgi K, She F, Datto C, Eriksson H. Double-blind, randomized study of extended release quetiapine fumarate (quetiapine XR) monotherapy in olderpatients with generalized anxiety disorder. Int $J$ Geriatr Psychiatry. 2013 Jun;28(6):61525. Epub 2012 Oct 16. [PubMed] [CrossRef]

13. Gao K, Sheehan DV, Calabrese JR. Atypical antipsychotics in primary generalized anxiety disorder or comorbid with mood disorders. Expert Rev Neurother. 2009 Aug;9(8):1147-1158. [PubMed] [CrossRef]

14. Diala CC, Muntaner C. Mood and anxiety disorders among rural, urban, and metropolitan residents in the United States. Community Ment HLT J. 2003 Jun;39(3):239-252. [PubMed] [CrossRef]

15. Wolitzky-Taylor KB, Castriotta N, Lenze EJ, Stanley MA, Craske MG. Anxiety disorders in older adults: a comprehensive review. Depress Anxiety. 2010 Feb;27(2):190-211. [PubMed] [CrossRef]

\author{
Address for correspondence: \\ Mariana Arnaudova-Jekova, MD, PhD \\ Third Psychiatric Clinic MHAT "St. Marina" \\ 1, Hristo Smirnenski str, 9010 Varna, Bulgaria \\ mobile: +359/888 512627 \\ e-mail: marnaudova@hotmail.com,
}

